\title{
Cross Sectional Survey of Care Seeking For Acute Respiratory IIIness in Children Under 5 Years in Rural Kenya
}

\author{
Elizabeth Wanjiku Ndungu ${ }^{1}$, Florence Nafula Okwara ${ }^{2}$, John Paul Oyore ${ }^{1}$ \\ ${ }^{1}$ Department of Community Health, Kenyatta University, Nairobi, Kenya \\ ${ }^{2}$ Department of Paediatrics and Child Health, Kenyatta University, Nairobi, Kenya
}

Email address:

libbyndungu@gmail.com (E. W. Ndungu)

\section{To cite this article:}

Elizabeth Wanjiku Ndungu, Florence Nafula Okwara, John Paul Oyore. Cross Sectional Survey of Care Seeking For Acute Respiratory Illness in Children Under 5 Years in Rural Kenya. American Journal of Pediatrics. Vol. 4, No. 3, 2018, pp. 69-79.

doi: 10.11648/j.ajp.20180403.15

Received: September 6, 2018; Accepted: September 19, 2018; Published: October 12, 2018

\begin{abstract}
Acute respiratory infection (ARI) is a leading cause of childhood morbidity and mortality in developing countries. In Kenya, diagnosis and treatment of ARI remains predominantly health facility based. This presumes that caretakers can recognize ARI symptoms promptly and make a decision to take the child to an appropriate health facility for treatment. Unfortunately, these presumptions have not been assessed. This study sought to establish determinants of health care seeking among caretakers of children under five years (CU5) of age with ARI. An analytic cross sectional survey was carried out in Githunguri Sub - County of Kiambu County. Households with CU5 who had recently suffered an episode of ARI were enrolled. Structured questionnaires, focused group discussions and key informant guides were used to gather information. Structured questionnaires were administered to caretakers to obtain information on socio-demographics, knowledge and health seeking practices. Bivariate and multivariate analysis was carried out with a p value of $<0.05$. From 438 households sampled, $323(73.7 \%)$ had CU5 in their households. Out of these, 240 (74.3\%) of the children had an episode of ARI in the preceding 2 weeks. The mean age of the children was 29.2 months, with male to female ratio of 1:1. The mean mothers' age was 29.4 years, $71.2 \%$ were married, $54.8 \%$ had secondary education and $66.6 \%$ were of Christian-protestants faith and (90.0\%) were in informal employment. Poor knowledge of pneumonia was documented in $92.5 \%$ of caretakers. One hundred and forty nine (62.1\%) caretakers had delayed health facility consultation for ARI. The main factors associated with delayed facility consultation were poor knowledge of symptoms $(p=0.007)$ long distance to the nearest health facility $(p=0.002)$, means of transport used to access the nearest health facility $(p=0.001)$ and previous high expenditure at health facility $(p=0.011)$. On logistic regression, the main factors that independently determined delayed facility consultation were long waiting time ( $>1$ hour) before service provision $(\mathrm{p}=0.001)$, use of a motorbike to access the nearest health facility $(\mathrm{p}=0.001)$ and traveling for $4-4.9$ kilo meters to the nearest health facility $(\mathrm{p}=0.002)$. Travelling for long distance and long waiting time before service provision during the previous facility visit were the main determinants of delayed facility consultations. The study recommends increased sensitization on symptom recognition among caretakers, and intensified efforts to reduce turn-around time during health facility consultations in order to minimize delays in health facility consultation.
\end{abstract}

Keywords: Acute Respiratory Illness, Children Under Five Years, Health Facility Consultation

\section{Background}

Worldwide, acute respiratory infections (ARI) are a leading cause of morbidity and mortality. Globally, 5.9 million children under 5 died in 2016, which translates to 16,000 deaths every day [1]. South East Asia reported the highest burden, followed by Africa at 0.36 and 0.3 episodes per child-year, compared to 0.06 in Europe [2]. Approximately $60 \%$ of pneumonia deaths occur in sub Saharan-Africa and South East Asia [3]. In Kenya the estimated National ARI prevalence was at $65.3 \%$. Pneumonia was among the leading cause of deaths among children under 
the age of five years accounting for $17 \%$ of these deaths [4]. Disproportionately higher rates of mortality due to pneumonia occur in rural settings, mostly attributed to poverty, poor housing and malnutrition [5]. Among strategies adopted to reduce pneumonia mortality, World Health Organization through Global Alliance of Vaccine and Immunization recommended introduction of pneumococcal vaccine in developing countries. While this had impact on morbidity and mortality, reduction of mortality among CU5 due to pneumonia has been slow (58\%) compared to the other diseases like measles (which had an $83 \%$ drop) and diarrhea (with a $68 \%$ decline) [6]. Moreover, according to the Global Action Plan for Prevention and Control of Pneumonia and Diarrhea progress report on pneumonia intervention coverage, Kenya had achieved a $66 \%$ coverage score against the recommended coverage score of $86 \%$ [7].

According to WHO and UNICEF joint statement on integrated Community Case Management (iCCM), survival of pneumonia depends on three essential steps. These steps entail timely recognition of signs and symptoms, prompt and appropriate care seeking and timely provision of a full course of antibiotic treatment. Caretakers play an important role, especially in recognition of symptoms and in prompt and appropriate care seeking. Unfortunately, only 1 in every 5 caretakers in developing countries can recognize the 2 symptoms of pneumonia, namely fast breathing, and difficulty in breathing [8]. Appropriate care seeking for childhood pneumonia has been low. Globally, only $58 \%$ of those children who had pneumonia/ARI symptoms were taken to a health care provider in 2014. This was much lower in developing countries, where only $47 \%$ sought appropriate care [9]. However, in Kenya, approximately $66 \%$ of CU5, who had ARI symptoms, were taken to an appropriate health care provider. As such, to avert pneumonia deaths, care seeking must not only be appropriate but also prompt. Timely care seeking from an appropriate provider helps in reducing disease morbidity and the risk of mortality. Health care seeking may be influenced by various factors ranging from individual factors, social factors and service based factors. In addition, survival of community acquired ARI is dependent on complex interaction of numerous mediators; among these are caretaker knowledge, virulence of bacterial pathogens, child vulnerability and prompt action by caretaker. Unfortunately, some of the presumptions have not been assessed locally. This study set out to assess determinants of health facility consultation for children presenting with ARI symptoms in rural Kenya.

\section{Materials and Methods}

\subsection{Study Setting and Design}

Data in the present study was collected among community members of Githunguri Sub - County, Kiambu County,
Kenya. It is a rural area and 1 of the $12 \mathrm{Sub}$ - Counties in Kiambu County. This Sub-County covers approximately $173.50 \mathrm{~km} 2$. In 2014, this Sub - County had a total population of 160,315 persons while the total number of CU5 was approximately 20,200 [10]. An analytical cross sectional study design was used to collect data on determinants of timely health facility consultation for ARI among CU5. Data was collected in the 3 divisions of Githunguri Sub - County namely; Githunguri, Ikinu and Komothai. These divisions had 4, 5 and 2 functional community units (CUs) respectively at the time of the study. The names are, Githunguri 1, Githunguri 2, Kimathi, Nyaga, Githiga, Matuguta, Gathangari, Kiababu, Ikinu, Kibichoi and Mbari -ya - Igi. In each of these community units, a list of all the households was generated by the community health workers (CHWs) per unit. Simple random sampling was used to sample households with CU5. Proportionate sampling was done per community unit, based on the total population of the households with CU5 generated.

\subsection{Study Population}

This included children under the age of five and the respondents being caretakers of these children.

\subsection{Enrollment of Study Participants}

Participant enrollment started from November 2014 to December 2014. A total of 438 households were sampled. Four hundred and two (402) had CU5 in their households, but only 353 were eligible and consented to participate in this study. Out of the 353, thirty had chronic conditions and were excluded from participating in this study. Hence, 323 households with CU5 in their households fully met the inclusion criteria. The flow chart of enrollment of study participants is presented in Figure 1.

Health care workers (nurses, doctors and clinical officers) were also enrolled to participate as key informants in order to gather more information on health service delivery factors influencing health care seeking behaviors among caretakers of CU5. Twelve health officials were purposively sampled as the key informants. Each was a representative of a community health unit. A key informant interview guide was used to collect information on health facility factors such as availability of trained staff, availability of equipment and medications, incurred costs at the facility and timing of health consultation by caretakers. Three focused group discussions (FGDs) were carried out among caretakers who had not participated earlier in the study. Each FGD had 15 members with at least 3 representatives from each community unit in the 3 divisions. Purposive sampling was carried out in selection of the caretaker's representative. 


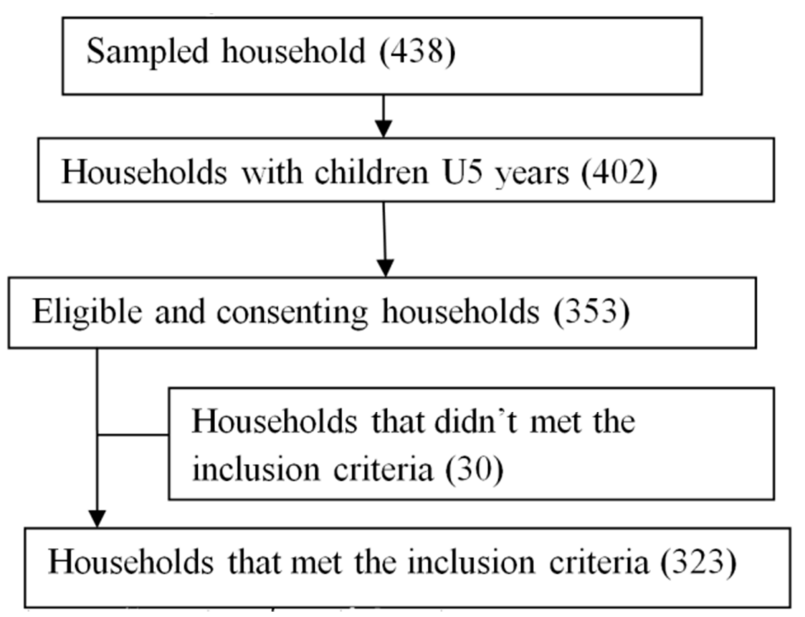

Figure 1. Study participants enrollment.

\subsection{Selection Criteria}

\subsubsection{Inclusion Criteria}

All consenting caretakers of CU5 who resided in Githunguri Sub-County and whose children had symptoms of ARI two weeks prior the study period were included in this study.

\subsubsection{Exclusion Criteria}

Caretakers whose CU5 had a pre-existing diagnosed chronic condition were excluded. To identify this, caretakers were asked if the child was being treated for another medical condition that required them to attend clinic days. If they answered yes, this called for exclusion to the study.

\subsection{Outcome Measurement}

The outcome variable for this study was timing of health facility consultation for ARI. Caretakers were asked to state how long they took after recognition of ARI symptoms to seek care at the health facility. This was to determine if timing of care was delayed or prompt. Prompt health facility consultation was identified when a sick child received appropriate health care within 24 hours of symptom recognition while delayed health facility consultation meant health facility consultation after more than 24 hours of signs and symptom recognition. ARI was defined as an illness characterized with symptoms of cough, accompanied by fast and/or difficulty in breathing. Caretakers were asked for occurrence of ARI in their children. Those with pre-existing chronic conditions were excluded. For those households reporting ARI episodes, a structured questionnaire was administered to the caretaker. This sought information on the socio-demographics and health seeking practices during the child's illness. This was based on the health belief model for behavior change. An appropriate health facility was attendance to a registered health center, clinic, or hospital. A hospital was defined as any health facility from the level of a District that is level 4, level 5 and level 6 hospital where admission services for the general and special conditions is available.

\subsection{Data Collection and Analysis}

Data used for analysis in this study emanate from the interviews conducted with the 323 caretakers for their CU5 and also from key informants and FGDs discussants. Collected data was coded, entered and analyzed using Statistical software; SPSS version 21. Baseline contacts and source characteristics were presented as frequencies, percentages, means and ratios. For each child, proportions were calculated regarding whether the child had an ARI symptom or not (Yes or No) in the last two weeks. Information on whether treatment was sought was also inquired and recorded as a (Yes or No) response. Enquiry on place of care (Health facility, Chemist or Shop), decision maker for care seeking (Respondent/Mother, Father/partner, Respondent mother, other (Mother - in - law, Friends), and timing of consultation (Same day, Next day, Two days, Three or more days) was done.

Socio-demographics, level of pneumonia knowledge and facility factors were also assessed as determinants of health facility consultation. Proportions were calculated for these factors and bivariate chi-square test $(p<0.05)$ calculated to assess association of these variables with timing of the health facility consultation. Variables that showed statistical significant association during chi- square test were included in multivariate logistic regression to assess the strongest independent predictor of timing of health facility consultation. The findings were presented as Odds Ratio with confidential interval levels and statistical significance calculated at $\mathrm{P}$ value $<0.05$.

On socio-demographics, enquiry was done in regards to age in months and gender of the child (male or female). Data on caretaker's age in years, marital status (Married, Single, Separated/Divorced or widowed), religious status (Protestant, Roman Catholic or Others; Wakurino, Muslims), source of income (Salaried or Non- salaried; casual laborers, crop farming and animal husbandry) and education level (No formal, Primary, Secondary, College/university) was also assessed. Regarding caretaker level of pneumonia knowledge, enquiry on causation, risk factors, signs and symptoms and prevention was done. A "knowledge index" was used to judge caretaker's level of knowledge on pneumonia. Each question on knowledge was weighted based on number of responses. For a question with only one correct answer, a score of 1 was awarded for a correct answer, and 0 for a wrong answer. For those questions with $>2$ possible responses, participant that got more than half the responses correct, was termed as having good knowledge, while the opposite implied poor knowledge. Health service delivery factors were also assessed. Enquiry on the nearest health facility characteristics like ownership (Government or Private), type of the health facility (Clinic, Dispensary, Health center, Hospital), distance to the nearest health facility in kilometers $(<1,1-1.9,2-2.9,3-3.9,4-4.9, \geq 5)$, Means of transport used to reach the nearest health facility (by Foot, Public; (Matatu, motor bike, taxi) or Private) was carried out. In addition, past experiences at the health facility to include 
costs incurred in previously at the health facility (buying children card, doctors consultation, buying medications), total cost in US Dollar ( $\leq 2$ or $>2)$, and turn - around time at the health facility in hours $(\leq 1$ or $>1)$ were also assessed

Qualitative data gathered during FGDs and key informant interview was analyzed through content analysis of key thematic areas and was presented in verbatim form.

\subsection{Ethical Considerations}

Ethical approval to carry out the research was granted by the Kenyatta University Ethical Research Committee (Reference number: KU/R/COMM/51/362). A research permit was obtained from the National Council for Science, Technology and Innovation (Reference number: NACOSTI/P/14/4674/3923). Further, research approval was obtained from Kiambu County Commissioner (Reference number: ED.12/1/VOL II/53) and County Director of Health Research (Reference number: KBU/COUNTY/RESEARCHAUTHO/VOL1/6).

Participation in this study was voluntary and participants who agreed to participate were asked to sign or thumb-print the informed consent form before commencing the study. Group consent was obtained for FGDs. Confidentiality and privacy was maintained during data collection and handling. Interviews were undertaken with individual study participants in their homes or household. All data collected was stored, analyzed and reported in formats that did not allow identification of the individual participant.

\section{Results}

\subsection{Study Participants Characteristics}

Data analysis included 323 caretakers of CU5s all of which were the biological mothers. From the sampled household only one child who was less than five years was selected for inclusion. Eighty $(24.8 \%)$ had their children aged between 13 to 24 months, but mean age was 29.2 months. Male children were $(170,52.6 \%)$, while $(153,47.4 \%)$ were females. Most of the study participants 160 (49.5\%) were aged between 20 to 29 years, with a mean age of 29.4 years. Majority, (230, 71.2\%) were married. Up to 177 (54.8\%) had achieved secondary level of education, 92 (28.5\%) had attained primary education $33(10.2 \%)$ had no formal education and only $21(6.5 \%)$ had achieved their college/ tertiary level of education. Most, 215 (66.6\%) were of Christian-protestant faith. Regarding their source of income, 291, (90\%) engaged in informal employment as casual laborers, crop farming and animal husbandry, while only (32, $10 \%$ ) had salaried employment. This is presented in Table 1.

Table 1. Participant's Characteristics.

\begin{tabular}{|c|c|c|c|}
\hline Characteristic & Categories & Frequency n (323) & Percentage $\%$ \\
\hline \multirow{5}{*}{ Child's age (in completed months) } & $0-12$ & 64 & 19.8 \\
\hline & $13-24$ & 80 & 24.8 \\
\hline & $25-36$ & 79 & 24.5 \\
\hline & $37-48$ & 50 & 15.5 \\
\hline & $49-59$ & 50 & 15.5 \\
\hline \multirow{2}{*}{ Child's sex } & Male & 175 & 54.2 \\
\hline & Female & 148 & 45.8 \\
\hline \multirow{3}{*}{ Mother's age (in completed years) } & $20-29$ & 160 & 49.5 \\
\hline & $30-39$ & 118 & 36.5 \\
\hline & $>40$ & 36 & 11.1 \\
\hline \multirow{4}{*}{ Marital status } & Single/never married & 78 & 24.1 \\
\hline & Married & 230 & 71.2 \\
\hline & Divorced/separated & 11 & 3.4 \\
\hline & Widowed & 4 & 1.2 \\
\hline \multirow{2}{*}{ Education level } & Secondary & 177 & 54.8 \\
\hline & College/University & 21 & 6.5 \\
\hline \multirow{3}{*}{ Religion } & Protestant & 215 & 66.6 \\
\hline & Roman Catholic & 79 & 24.5 \\
\hline & Others & 29 & 9.0 \\
\hline \multirow{2}{*}{ Source of income } & No salaried & 291 & 90.0 \\
\hline & Salaried employment & 32 & 10.0 \\
\hline
\end{tabular}

\subsection{ARI Prevalence and Care Seeking}

Two hundred and forty (74.3\%) children had a cough and fast breathing 2 weeks prior the study. the rest $(83,25.7 \%)$ had symptoms of nasal congestion, chest congestion and a running nose. All children who had ARI symptoms were taken to a health facility for check up. On timing of health consultation, 149 (62.1\%) delayed visiting a health facility while only (91,
$37.9 \%$ ) visited a health facility promptly. Among those that delayed visiting a health facility, 80(53.7\%) took 1 day, 47 (31.5\%) took 2 days and 22(14.8\%) took at least 3days. Regarding the facility sought, majority $(170,70.8 \%)$ sought care in a health center, $39(16.2 \%)$ in a dispensary while $31(12.9 \%)$ sought care in a hospital. Biological mothers were the key decision makers $(151,62.9 \%)$ in regards to care seeking. However, child's father $(30,12.5 \%)$ and Mother in law and 
friends $(59,24.6 \%)$ also had some little influence on choice of care for the sick child in some cases. Timing of health facility consultation was measured among those children who had ARI. Of the 240 children with ARI, $(149,62.1 \%)$ delayed visiting a health facility, while $(91,37.9 \%)$ visited a health facility promptly. Among those who had delayed visiting a health facility, $(80,53.7 \%)$ took 1 day, $(47,31.5 \%)$ took 2 days and $(22,14.8 \%)$ took $\geq 3$ days to seek appropriate care. This is presented in Table 2.

Majority delayed seeking appropriate care for their children. During FGDs with the caretakers, most reiterated that they made the decision to seek care but they had to wait for their husbands to provide. "I am always with (child name) so I am able to see when he gets sick. But, I have to inform his father before I seek care for financial provision" a focus group discussant. Another focused group discussant reported as follows, "After noticing (child name) was sick I waited for three days before going to a health facility, because, I depend on his father for finances". More insight on timing of health care consultation was revealed during Key Informant Interviews (KIIs) with Health Care Workers (HCWs). One of the $\mathrm{HCW}$ reported, "Mothers know that they should come to the health facility immediately when they recognize their child is not feeling well. However, most of them seek health facility care after three or four days of symptoms recognition". Moreover, during in-depth interview with the HCWs, it was noted that most mothers use alternative treatments before seeking care at the health facility. One of the HCW reported the following, "Mothers always delay seeking care for their children even if they know that health facility care is the best. Most of them use home remedies and only come to us when the illness complicates". Another key informant reported as follows, "Mothers know that children should be brought to the health care facility immediately when sick. Most of them however, opt to buy cold cap and piriton at the shop for cough and only come to us (health facility) when the condition worsens".

Table 2. ARI prevalence and care seeking.

\begin{tabular}{|c|c|c|c|}
\hline Characteristic & Categories & Frequency (n) & Percentage $\%$ \\
\hline \multirow{2}{*}{ Sick with ARI symptoms* } & Yes & 240 & 74.3 \\
\hline & No & 83 & 25.7 \\
\hline \multirow{3}{*}{ Place care was sought ${ }^{* *}$} & Hospital & 31 & 12.9 \\
\hline & Health center & 170 & 70.8 \\
\hline & Dispensary & 39 & 16.2 \\
\hline \multirow{3}{*}{ Key decision maker for care seeking } & Mother & 151 & 62.9 \\
\hline & Father & 30 & 12.5 \\
\hline & Mother in law/relatives & 59 & 24.6 \\
\hline \multirow{2}{*}{ Timing of health facility consultation ${ }^{* *}$} & Delayed & 149 & 62.1 \\
\hline & Prompt & 91 & 37.9 \\
\hline \multirow{3}{*}{ Level of delay (in days) ${ }^{* * *}$} & 1 & 80 & 53.7 \\
\hline & 2 & 47 & 31.5 \\
\hline & $\geq 3$ & 22 & 14.8 \\
\hline
\end{tabular}

$* \mathrm{n}$ equals to 323 participants, $* *$ n equals to 240 participants, $* * *=\mathrm{n}$ equals to 149 participants

\subsection{Caretakers Level of Pneumonia Knowledge}

Enquiry on causation, risk factors, signs and symptoms and prevention of pneumonia was done to determine caretaker's level of knowledge. When asked what causes pneumonia, $(142,59.2 \%)$ reported it was due to cold temperature, $(90,37.5 \%)$ said it was due to changes in climate, while only $(38,15 \%)$ said it was caused by a virus or bacteria. When asked to list the risk factors of pneumonia, $(152,63.3 \%)$ reported cold to be one of the risk factors, $(54$, $22.5 \%)$ listed malnutrition and $(45,18.8 \%)$ listed lack of vaccination. On their knowledge of pneumonia symptoms, $(115,47.9 \%)$ reported cough as a common symptom, and $(104,43.3 \%)$ reported difficulty/fast breathing. This data was then scored to determine the level of pneumonia knowledge. Regarding causation of pneumonia, which had only one correct response $(209,87.1 \%)$ had poor knowledge. On knowledge of risk factors, which had 7 possible responses, majority, (237, 98.8\%) knew less than $50 \%$ of the correct responses while only $(3,1.2 \%)$ knew more than $50 \%$ correct responses. Out of 5 correct possible responses regarding symptoms of pneumonia, majority $(179,74.6 \%)$ could not list half of these responses even when read out loud for them. On pneumonia prevention, most $(208,86.7 \%)$ had poor knowledge. Overall, there was poor knowledge of pneumonia reported in 222(92.5\%) of caretakers. On specific pneumonia knowledge, there was poor knowledge on causation $209(87.1 \%)$, risk factors $237(98.8 \%)$, prevention $208(86.7 \%)$ and symptoms and signs $179(74.6 \%)$ of pneumonia (Table 3 ). Generally mothers had poor knowledge of pneumonia. Similarly, during FGDs it was noted that mothers lacked the correct information of pneumonia causation and symptoms. "Cold was the main reason (name of the child) developed a cough. I was not worried about the cough at first, but after two days, the cough was not over and the child was unable to breathe well. So I went to the health facility for him to be seen" a focused group discussant report. Another focused group discussant reported as follows, "When (child name) developed a cough and fever, I thought it was "homa" (common cold). It was at night so I bought piriton and gave him. In the morning he was still unwell. His breathing was noisy. I then decided to take him to the health center." 
Table 3. Caretakers knowledge on pneumonia.

\begin{tabular}{|c|c|c|c|}
\hline \multicolumn{4}{|c|}{ Caretakers pneumonia knowledge } \\
\hline Variable & & Frequency $(n=240)$ & Percentage (\%) \\
\hline \multirow{2}{*}{ Causes } & Poor & 209 & 87.1 \\
\hline & Good & 31 & 12.9 \\
\hline \multirow{2}{*}{ Risk factors } & Poor & 237 & 98.8 \\
\hline & Good & 3 & 1.2 \\
\hline \multirow{2}{*}{ Signs } & Poor & 179 & 74.6 \\
\hline & Good & 61 & 25.4 \\
\hline \multirow{2}{*}{ Prevention } & Poor & 208 & 86.5 \\
\hline & Good & 32 & 13.5 \\
\hline Overall & Poor & 222 & 92.5 \\
\hline knowledge & Good & 18 & 7.5 \\
\hline
\end{tabular}

\subsection{Health Service Delivery Factors}

The nearest health facility for majority of the caretakers was owned by the government $(223,93.3 \%)$. Health center was the most common $(185,77.1 \%)$ type of health facility near the study participants place of residence, followed by a dispensary $(38,15.8 \%)$ and finally a District hospital (17, $7.1 \%)$. Majority $(185,77.1)$ resided less than 4 kilometers from the nearest health facility while the rest $(55,22.9 \%)$ more than 4 kilometers. Most of the caretakers used public means of transport to access the nearest health facility; eighty one $(33.8 \%)$ said that they used matatu/buses, $58(24.2 \%)$ motorbikes, $41(17.1 \%)$ taxi while $39(16.2 \%)$ walked and 21
(8.8\%) used personal means. To determine caretaker experiences at their nearest health facility, we asked them about costs incurred previously and computed the total cost. In addition, caretakers were asked to indicate how long it took for them to be assisted and also to state the general status of service provision during their previous visit at the facility. Majority $(194,80.8 \%)$ had used. $\geq 2$ USD to cater for cost of care for their child at the health facility in the previous visit. Caretakers were said to have incurred high cost of care if they used $>2$ USD, while the opposite implied low cost. This was based on the average daily income. Most caretakers had no salaried income in this study. Their average daily income therefore was between 1.5 to 2.5 USD (which is equivalent to 150 to 250 Kenya Shillings). Three quarters, $(184,76.7 \%)$ had waited for $\leq 1 \mathrm{hr}$, while $(56,23.3 \%)$ waited for $>1 \mathrm{hr}$ before being assisted at the health facility in the previous visit. Caretakers were said to have had experienced delayed assistance/facility delays if they had waited for $>1 \mathrm{hr}$ at the health facility. The opposite implied prompt assistance. With regards to previous status of care at the health facility, majority $(219,91.2 \%)$ reported that they lacked medication for their child. The rest $(21,8.8 \%)$ said they experienced delays at the health facility and attributed this to long queues and few staffs. This is presented in Table 4 .

Table 4. Health service delivery characteristics.

\begin{tabular}{|c|c|c|c|}
\hline Characteristic & Categories & Frequency $(n=240)$ & Percentage \% \\
\hline \multicolumn{4}{|l|}{ Nearest health facility characteristics } \\
\hline \multirow{3}{*}{ Ownership } & Private & 16 & 6.7 \\
\hline & Government & 223 & 93.3 \\
\hline & District hospital & 17 & 7.1 \\
\hline \multirow[t]{4}{*}{ Type } & Health Centre & 185 & 77.1 \\
\hline & Dispensary & 38 & 15.8 \\
\hline & $<1$ & 28 & 11.7 \\
\hline & $1-1.9$ & 56 & 23.3 \\
\hline \multirow{6}{*}{ Distance (in kilometers) } & $2-2.9$ & 66 & 27.5 \\
\hline & $3-3.9$ & 35 & 14.6 \\
\hline & $4-4.9$ & 19 & 7.9 \\
\hline & $>5$ & 36 & 15.0 \\
\hline & By foot & 39 & 16.2 \\
\hline & Bus/ Matatu & 81 & 33.8 \\
\hline \multirow[t]{3}{*}{ Means of transport } & Personal means & 21 & 8.8 \\
\hline & Taxi & 41 & 17.1 \\
\hline & Motorbike & 58 & 24.2 \\
\hline \multicolumn{4}{|l|}{ Past experience at the health facility } \\
\hline \multirow{4}{*}{ Costs incurred } & None & 31 & 12.9 \\
\hline & Buying children cards & 65 & 27.1 \\
\hline & Doctor's consultation & 17 & 7.1 \\
\hline & Buying medicines & 127 & 52.9 \\
\hline \multirow{2}{*}{ Total cost (in US Dollar) } & $<2<-2$ & 46 & 19.2 \\
\hline & $\geq 2$ & 194 & 80.8 \\
\hline \multirow{2}{*}{ Waiting time before being assisted (in hours) } & $<1$ & 184 & 76.7 \\
\hline & $\geq 1$ & 56 & 23.3 \\
\hline \multirow{3}{*}{ Status of care } & No available medication & 219 & 91.2 \\
\hline & few staff to attend us & 10 & 4.2 \\
\hline & Long queues/delays & 11 & 4.6 \\
\hline
\end{tabular}

\subsection{Determinants of Health Facility Consultation}

On bivariate analysis using chi-square test, among sociodemographic factors, child's gender $(\mathrm{P}=0.036)$ and key decision maker for care seeking $(\mathrm{P}=0.014)$ were statistically associated with health facility consultation. The rest, child's age $(p=0.276)$, mother's age $(p=0.614)$, marital status $(p=$ 0.747), occupation $(P=0.125)$ and level of education $(p=$ 
0.476) were not associated with timing of health facility consultation. A few 19 (7.9\%) belonged to non- conventional religious group, some of which barred their members from seeking health facility care. However, religion was not associated with delayed consultation $(p=0.926)$. This is presented in Table 5.

Table 5. Socio-demographic factors as determinants of health facility consultation.

\begin{tabular}{|c|c|c|c|c|c|c|}
\hline \multirow{3}{*}{ Variable } & & \multicolumn{4}{|c|}{ Timing of health consultation $(n=240)$} & \multirow{3}{*}{ Chi-square test } \\
\hline & & \multicolumn{2}{|c|}{ Delayed } & \multicolumn{2}{|c|}{ Prompt } & \\
\hline & & $\mathbf{N}$ & $\%$ & $\mathbf{N}$ & $\%$ & \\
\hline \multirow{5}{*}{$\begin{array}{l}\text { Age of the child } \\
\text { (in completed months) }\end{array}$} & $0-12$ & 26 & 63.4 & 15 & 36.6 & \multirow{5}{*}{$\begin{array}{l}\chi^{2}=5.115, \mathrm{df}=4 \\
P=0.276\end{array}$} \\
\hline & $13-24$ & 43 & 71.7 & 17 & 28.3 & \\
\hline & $25-36$ & 36 & 59.0 & 25 & 41.0 & \\
\hline & $37-48$ & 24 & 63.2 & 14 & 36.8 & \\
\hline & $49-60$ & 20 & 50.0 & 20 & 50.0 & \\
\hline Child' gender & Female & 83 & 68.6 & 38 & 31.4 & $\begin{array}{l}\chi^{2}=4.396, \mathrm{df}=1 \\
P=0.036^{*}\end{array}$ \\
\hline \multirow{4}{*}{$\begin{array}{l}\text { Mother's age } \\
\text { (in completed years }\end{array}$} & $<19$ & 4 & 66.7 & 2 & 33.3 & \multirow{4}{*}{$\begin{array}{l}\chi^{2}=1.805, \mathrm{df}=3 \\
\mathrm{P}=0.614\end{array}$} \\
\hline & $20-29$ & 71 & 59.2 & 49 & 40.8 & \\
\hline & $30-39$ & 53 & 62.4 & 32 & 37.6 & \\
\hline & $>40$ & 21 & 72.4 & 8 & 27.6 & \\
\hline \multirow{2}{*}{ Marital status } & Single/never married & 34 & 58.6 & 24 & 41.4 & \multirow{2}{*}{$\begin{array}{l}\chi^{2}=1.226, \mathrm{df}=3 \\
P=0.747\end{array}$} \\
\hline & Married & 108 & 63.5 & 62 & 36.5 & \\
\hline \multirow{4}{*}{ Education level } & No formal education/ & 16 & 66.7 & 8 & 33.3 & \multirow{4}{*}{$\begin{array}{l}\chi^{2}=2.496, \mathrm{df}=3 \\
P=0.476\end{array}$} \\
\hline & Primary completed & 45 & 66.2 & 23 & 33.8 & \\
\hline & Secondary complete & 77 & 57.9 & 56 & 42.1 & \\
\hline & College/University & 11 & 73.3 & 4 & 26.7 & \\
\hline \multirow{3}{*}{ Religion } & Protestant & 95 & 62.5 & 57 & 37.5 & \multirow{3}{*}{$\begin{array}{l}\chi^{2}=0.154, \mathrm{df}=2 \\
P=0.926\end{array}$} \\
\hline & Roman Catholic & 43 & 62.3 & 26 & 37.7 & \\
\hline & Others & 11 & 57.9 & 8 & 42.1 & \\
\hline \multirow{2}{*}{ Source of income (Occupation) } & Non salaried & 137 & 63.7 & 78 & 36.3 & \multirow{2}{*}{$\begin{array}{l}\chi^{2}=2.351, \mathrm{df}=1 \\
P=0.125\end{array}$} \\
\hline & Salaried & 12 & 48.0 & 13 & 52.0 & \\
\hline \multirow{3}{*}{ Key decision maker for care } & Mother & 85 & 56.3 & 66 & 43.7 & \multirow{3}{*}{$\begin{array}{l}\chi^{2}=8.530, \mathrm{df}=2 \\
\mathrm{P}=0.014\end{array}$} \\
\hline & Father & 18 & 60.0 & 12 & 40.0 & \\
\hline & Mother in law/ Relatives & 46 & 78.0 & 13 & 22.0 & \\
\hline
\end{tabular}

*Significant at $\mathrm{p}<0.05$

During FGDs, most caretakers considered pneumonia as a serious childhood illness. They knew that the commonest symptoms of pneumonia were a cough and difficulty in breathing. None the less, most associated it with exposure to cold and therefore they mostly intervened by keeping the child warm or administering warm drinks. This is what some Caretakers reiterated, "Cold was the main reason (name of the child) developed a cough. I was not worried about the cough at first, but after two days, the cough was not over and the child was unable to breathe well. So I went to the health facility for him to be seen" a focused group discussant.
Another focused group discussant reported as follows, "When (child name) developed a cough and fever, I thought it was "homa" (common cold). It was at night so I bought piriton and gave him. In the morning he was still unwell. His breathing was noisy. I then decided to take him to the health center." On bivariate analysis of knowledge level and timing of hospital consultation, the knowledge of symptoms of pneumonia was significantly associated prompt facility visit $(\mathrm{p}=0.007)$. Knowledge of causation of pneumonia $(\mathrm{p}=$ $0.059)$, prevention strategies for pneumonia $(p=0.130)$ were all not significant (Table 6).

Table 6. Knowledge of pneumonia as a determinant of health facility consultation.

\begin{tabular}{|c|c|c|c|c|c|c|}
\hline \multirow{3}{*}{ Variable } & & \multicolumn{4}{|c|}{ Timing of health consultation $(n=240)$} & \multirow{3}{*}{ Chi-square test } \\
\hline & & \multicolumn{2}{|c|}{ Delayed } & \multicolumn{2}{|c|}{ Prompt } & \\
\hline & & $\mathbf{N}$ & $\%$ & $\mathbf{N}$ & $\%$ & \\
\hline \multirow{2}{*}{ Causation } & Poor & 125 & 59.8 & 84 & 40.2 & $\chi^{2}=3.557, \mathrm{df}=1$ \\
\hline & Good & 24 & 77.4 & 7 & 22.6 & $\mathrm{p}=0.059$ \\
\hline \multirow{2}{*}{ Signs } & Poor & 120 & 67.0 & 59 & 33.0 & $\chi^{2}=7.348, \mathrm{df}=1$ \\
\hline & Good & 29 & 47.5 & 32 & 52.5 & $\mathrm{p}=0.007^{*}$ \\
\hline Prevention & Poor & 133 & 63.9 & 75 & 36.1 & $\chi^{2}=2.290, \mathrm{df}=1$ \\
\hline \multirow{2}{*}{ Overall total score } & Poor & 139 & 62.6 & 83 & 37.4 & $\chi 2=0.352, \mathrm{df}=1$ \\
\hline & Fair & 10 & 55.6 & 8 & 44.4 & $\mathrm{P}=0.553$ \\
\hline
\end{tabular}

*Significant at $\mathrm{p}<0.05$ 
During KIIs, enquiry into the overall turn-around time at the facility was about 2 hrs. Large work-loads and staff shortages were the main reasons. Drug shortages at the facilities were a common scenario in these facilities, and patients were given prescriptions to buy the medicines elsewhere. One of the key informants reported the following in regards to delayed assistance at the health facility. "Some time we delay seeing the sick children because of the work load and their high number. Of course this discourages the mothers from seeking care but what can we do bearing in mind we are very few". Another key informant reported as follows, "We are four staffs at this health facility, but only two of us report to work in a day. At times, one works as a laboratory technician, nurse and clinician. This is too much for one person to handle. Therefore, as much as we would want to assist the mothers with no delay, we can't". On bivariate analysis of health facility factors, those statistically significantly associated with delayed facility visit were long distance to the nearest health facility $(p=0.002)$, means of transport used to access the nearest health facility ( $p=$ $0.001)$, previous high expenditure at health facility ( $\mathrm{p}=$ $0.011)$, and long waiting time before being served during the previous visit $(\mathrm{P}=0.023)$ (Table 7).

Table 7. Health service delivery factors as determinants of health facility consultation.

\begin{tabular}{|c|c|c|c|c|c|c|}
\hline \multirow{3}{*}{ Variable } & & \multicolumn{4}{|c|}{ Timing of health consultation $(n=240)$} & \multirow{3}{*}{ Chi-square test } \\
\hline & & \multicolumn{2}{|c|}{ Delayed } & \multicolumn{2}{|c|}{ Prompt } & \\
\hline & & $\mathbf{N}$ & $\%$ & $\mathbf{N}$ & $\%$ & \\
\hline \multicolumn{7}{|l|}{ Nearest health facility characteristics } \\
\hline \multirow{2}{*}{ Ownership } & Private & 13 & 81.2 & 3 & 18.8 & \multirow{5}{*}{$\begin{array}{l}\chi^{2}=2.675, \mathrm{df}=1 \\
\mathrm{p}=0.102 \\
\chi^{2}=0.090, \mathrm{df}=2 \\
\mathrm{p}=0.956\end{array}$} \\
\hline & Government & 136 & 60.7 & 88 & 39.3 & \\
\hline \multirow{3}{*}{ Type } & District hospital & 20 & 64.5 & 11 & 35.5 & \\
\hline & Health Centre & 105 & 61.8 & 65 & 38.2 & \\
\hline & Dispensary & 24 & 61.5 & 15 & 38.5 & \\
\hline \multirow{7}{*}{ Distance (in kilometers) } & $<1$ & 12 & 42.9 & 16 & 57.1 & \multirow{7}{*}{$\begin{array}{l}\chi^{2}=18.713, \mathrm{df}=5 \\
\mathrm{p}=0.002 *\end{array}$} \\
\hline & $1-1.9$ & 34 & 60.7 & 22 & 39.3 & \\
\hline & $2-2.9$ & 49 & 74.2 & 17 & 25.8 & \\
\hline & $3-3.9$ & 14 & 40.0 & 21 & 60.0 & \\
\hline & $4-4.9$ & 13 & 68.4 & 6 & 31.6 & \\
\hline & $>5$ & 27 & 75.0 & 9 & 25.0 & \\
\hline & By foot & 26 & 66.7 & 13 & 33.3 & \\
\hline \multirow{4}{*}{ Means of transport } & Bus/ Matatu & 55 & 67.9 & 26 & 32.1 & \multirow{4}{*}{$\begin{array}{l}\chi^{2}=19.530, \mathrm{df}=4 \\
\mathrm{p}=0.001 *\end{array}$} \\
\hline & Personal means & 15 & 71.4 & 6 & 28.6 & \\
\hline & Taxi & 13 & 31.7 & 28 & 68.3 & \\
\hline & Motorbike & 40 & 69.0 & 18 & 31.0 & \\
\hline \multicolumn{7}{|l|}{ Past experience at the health facility } \\
\hline \multirow{4}{*}{ Costs incurred } & None & 21 & 67.7 & 10 & 32.3 & \multirow{4}{*}{$\begin{array}{l}\chi^{2}=3.221, \mathrm{df}=3 \\
\mathrm{p}=0.359\end{array}$} \\
\hline & Buying children cards & 45 & 69.2 & 20 & 30.8 & \\
\hline & Doctor's consultation & 9 & 52.9 & 8 & 47.1 & \\
\hline & Buying medicines & 74 & 58.3 & 53 & 41.7 & \\
\hline \multirow{2}{*}{ Total cost (in USD) } & $\leq 2$ & 128 & 66.0 & 66 & 34.0 & \multirow{2}{*}{$\begin{array}{l}\chi^{2}=6.527, \mathrm{df}=1 \\
\mathrm{p}=0.011 *\end{array}$} \\
\hline & $>2$ & 21 & 45.7 & 25 & 54.3 & \\
\hline \multirow{2}{*}{ Waiting time before assistance (in hours) } & $<1$ & 107 & 58.2 & 77 & 41.8 & \multirow{4}{*}{$\begin{array}{l}\chi^{2}=5.177, \mathrm{df}=1 \\
P=0.023^{*} \\
\chi^{2}=0.854, \mathrm{df}=1 \\
P=0.355\end{array}$} \\
\hline & $\geq 1$ & 42 & 75.0 & 14 & 25.0 & \\
\hline & No available medication & 134 & 61.2 & 85 & 38.8 & \\
\hline Status of care & others (few staff/ long queues) & 15 & 71.4 & 6 & 28.6 & \\
\hline
\end{tabular}

*Significant at $\mathrm{p}<0.05$

Variables that were significantly associated with delayed health facility consultation on bivariate analysis were included in multivariate analysis model, to identify which one was the independently significant. The strongest independent determinant of "health facility consultation for ARI" was long waiting time ( $>$ lhour) before service provision $(\mathrm{OR}=5.249 ;$ C.I $(1.997-13.796) ; \mathrm{p}=0.001)$, use of a motorbike to access the nearest health facility $(\mathrm{OR}=$ 52.057; C.I $(4.597-589.551) ; \mathrm{p}=0.001)$ and traveling for 4 -4.9 kilo meters to the nearest health facility $(\mathrm{OR}=6.354$; C.I $(1.950$ - 20.704); $\mathrm{p}=0.002)$. Details of independent predictors of delayed health facility visit for ARI are presented in Table 5.

Table 8. Independent determinants of health facility consultation.

\begin{tabular}{|c|c|c|c|c|c|}
\hline \multirow{2}{*}{ Independent variables } & & \multirow{2}{*}{ P value } & \multirow{2}{*}{ Odds Ratio (OR) } & \multicolumn{2}{|c|}{ Confidential interval for OR at $95 \%$} \\
\hline & & & & Lower & Higher \\
\hline Sex of child & $\begin{array}{l}\text { Male (Ref) } \\
\text { Female } \\
\text { Mother (Ref) }\end{array}$ & $\begin{array}{l}0.046 \\
0.103\end{array}$ & 1.896 & 1.013 & 3.550 \\
\hline Key decision maker for care seeking & $\begin{array}{l}\text { Father } \\
\text { Others }\end{array}$ & $\begin{array}{l}0.067 \\
0.054\end{array}$ & $\begin{array}{l}2.127 \\
2.845\end{array}$ & $\begin{array}{l}0.948 \\
0.982\end{array}$ & $\begin{array}{l}4.770 \\
8.241\end{array}$ \\
\hline
\end{tabular}




\begin{tabular}{|c|c|c|c|c|c|}
\hline \multirow{2}{*}{ Independent variables } & & \multirow{2}{*}{ P value } & \multirow{2}{*}{ Odds Ratio (OR) } & \multicolumn{2}{|c|}{ Confidential interval for OR at $95 \%$} \\
\hline & & & & Lower & Higher \\
\hline \multirow{2}{*}{ Knowledge on signs of pneumonia } & Poor (Ref) & & \multirow[b]{2}{*}{0.482} & \multirow{3}{*}{0.224} & \multirow[b]{2}{*}{1.035} \\
\hline & Good & 0.061 & & & \\
\hline \multirow{6}{*}{ Distance (in kilometers) } & $<1$ (Ref) & 0.018 & & & \\
\hline & $1-1.9$ & 0.014 & 6.056 & 1.431 & 25.623 \\
\hline & $2-2.9$ & 0.030 & 3.824 & 1.141 & 12.812 \\
\hline & $3-3.9$ & 0.261 & 1.917 & 0.616 & 5.969 \\
\hline & $4-4.9$ & 0.002 & 6.354 & 1.950 & 20.704 \\
\hline & $>5$ & 0.250 & 2.385 & 0.542 & 10.491 \\
\hline \multirow{5}{*}{ Means of transport } & By foot (Ref) & 0.030 & & & \\
\hline & Bus/ Matatu & 0.985 & 0.990 & 0.358 & 2.742 \\
\hline & Personal means & 0.502 & 1.377 & 0.541 & 3.501 \\
\hline & Taxi & 0.931 & 0.946 & 0.267 & 3.345 \\
\hline & Motorbike & 0.001 & 52.057 & 4.597 & 589.551 \\
\hline \multirow{2}{*}{ Total cost (in USD) } & $\leq 2(\operatorname{Ref})$ & & & & \\
\hline & $>2$ & 0.104 & 6.062 & 0.691 & 53.174 \\
\hline \multirow{2}{*}{ Waiting time before assistance (in hours) } & $<1$ (Ref) & & & & \\
\hline & $\geq 1$ & 0.001 & 5.249 & 1.997 & 13.796 \\
\hline
\end{tabular}

*Significant at $\mathrm{p}<0.05$

\section{Discussion}

Prevalence of ARI in this area was $74.3 \%$, slightly higher than the national prevalence of $65.9 \%$ [4], this could be attributed to maternal occupation as laborers in agricultural farms, to where they carried children along. Rural preponderance was also reported in a Ugandan study which reported rural and urban rates of ARI at $50 \%$ and $37 \%$ respectively [11]. Another study in Ethopia found ARI prevalence at $91 \%$ among rural dwellers [12]. On the contrary, an Indian study reported higher urban than rural rates at $63.7 \%$ and $53.7 \%$ respectively [13].

At least $62.1 \%$ of ARI cases had delayed hospital consultations. Use of home remedies and over- the-counter medications was the main reason for these delays. Similar findings were reported in studies done in Uganda and Ethiopia [14, 15] as well as studies in Pakistan and Albania $[16,17]$. Gender disparities still play a role in health seeking behaviours. Our findings revealed that caretakers were 1.8 times more likely to delay consulting a health facility if their child was a female than male. Similar findings were reported in studies done in Pakistan, India and Africa [16, 18, 19]. Surprisingly, age of child was not found to influence health facility consultation in this study. On the contrary, studies carried out in Sub-Saharan Africa, Pakistan and Indonesia all found age of the child to be associated with prompt care seeking for ARI/presumed pneumonia, [16, 19, 20]. In Kenya, according to KDHS, mothers level of education did not influence care seeking for childhood illness [4]. Likewise, caretaker's level of education was not found significant in this study. On the contrary, a study done in Nandi County, Kenya found low education level to be associated with care seeking delays [21]. In addition, other studies carried out in Pakistan, Yemen and Ethiopia did find level of education as a significant determinant to timing of health seeking for ARI $[16,22,23,24]$. Religious affiliations have been found to influence health facility consultations. In this study, a few religious cults barred their children from seeking health facility care. In a study carried out in rural Ethiopia, prompt care seeking was reported in Christian based than Muslim headed households [24]. Despite the fact that mothers were the key decision makers on health care seeking, they depended on the child's father for financial provision, which led to delays in care seeking. Similar findings were reported in studies done at Yemen and Niger where mothers were the key decision makers on care seeking, but relied on the child's father for financial provision. This caused further delays in seeking appropriate care for ARI $[23,25]$.

Overall, only $(18,7.5 \%)$ had good knowledge of pneumonia, and caretakers with poor knowledge were more likely to have delayed consultations. This concurs with findings from an earlier study done in rural Nandi, Kenya that showed that mothers sought prompt care if they were able to recognize difficulty in breathing and fast breathing in child, than a mere cough [26]. Similar findings were also reported in a study done in Ethiopia [15]. Majority (87.1\%) had poor knowledge of pneumonia causation, and (59.2\%) reported that it was due to cold temperature and therefore keeping the child warm could help relief the symptoms. Similar findings were reported in a study done in Nigeria that cold caused pneumonia and reducing its exposure and wearing warm clothes would prevent it [27].

Health facility factors strongly influenced facility consultation. Long waiting time before service provision at the health facility strongly determined timing of next consultation $(p=0.001)$. This was supported by KIIs reports that large workloads and few health personnel were among the main causes of delayed services. Similar findings were reported in a study carried out at Homa bay County, Kenya, where long queues or delays at the health facility were found to contribute to delays in seeking care at the hospitals [28]. Other studies done in South Africa, Australia and Central America also reported similar findings, [29, 30, 31, 32].

Health care cost has been cited as one of the barriers to health care seeking. Although the policy position that treatment of CU5s is free in all government health facilities, caretakers often have to purchase drugs elsewhere as often 
stock run out. Caretakers therefore, opt to buy over the counter medications before seeking care at these facilities, hence delays in consultation. Other studies done in Kenya reported similar findings [33, 34]. This has also been described in other studies from South Africa, Southeast Asia and Philistines [30, 35, 36].

Though, majority $(185,77.1)$ resided less than 4 kilometers from the nearest health facility, distance to these facilities was associated with delayed facility consultation. This could have been due to the poor terrain and roads forcing caretakers to use motorbikes to access the nearest health facility. Similarly, studies carried out in Kenya reported that poor access and long distances to be associated with delays in seeking appropriate care[34, 28]. Similar findings were reported in Southeast Asia, Australia and Philippine which found that mothers who traveled long distance to the facility, delayed or failed to seek health facility care for their child [31, 35, 37].

Large number of non-consenting households in this study may have influenced findings. In addition, this study was carried out over a limited period of time and therefore did not look at seasonal variations to ARI prevalence and determinants to health facility consultations.

\section{Conclusions}

The prevalence of ARI in Githunguri Sub-County among CU5s was high at $74.3 \%$, and most $149,(62.1 \%)$ had delayed health facility consultation. Overall, respondents had poor knowledge of pneumonia, and poor symptoms recognition was associated with delayed health facility consultation. Long distances to the nearest health facility and more so poor access to the nearest health facility were health facility characteristics that lead to delayed health fsacility consultation for ARI. Past experiences at the health facility, like high expenditure at health facility (due to lack of medication at the facility and caretakers had to buy) and long waiting time before being served by $\mathrm{HCW}$ sere strongly associated with current delay of care seeking. This study recommend increased sensitization on symptom recognition among caretakers, and intensified efforts to reduce turnaround time during health facility consultations in order to minimize delays in health facility consultation.

\section{Acknowledgements}

We appreciate the contribution of all participants who gave their time. We acknowledge the Ministry of Health officials, the Kiambu county health research Officer, for allowing us to undertake the study.

\section{References}

[1] WHO. World Health Organization Fact Dheet for Pneumonia - Google Search [Internet]. 2015 [cited 2016 Aug 16]. Available from: https://www.google.com/search?
[2] Rudan I, Boschi-Pinto C, Biloglav Z, Mulholland K, Campbell H. Epidemiology and etiology of childhood pneumonia. Bull World Health Organ. 2008;86(5):408-416B.

[3] Black RE, Cousens S, Johnson HL, Lawn JE, Rudan I, Bassani DG, et al. Global, regional, and national causes of child mortality in 2008: a systematic analysis. The lancet. 2010;375(9730):1969-1987.

[4] KDHS. Kenya Demographic Health Survey. 2014. kenya Google Search [Internet]. 2014 [cited 2016 Aug 17]. Available from: https://www.google.com/search?

[5] Bigogo GM, Breiman RF, Feikin DR, Audi AO, Aura B, Cosmas L, et al. Epidemiology of respiratory syncytial virus infection in rural and urban Kenya. J Infect Dis. 2013; 208 (suppl 3):S207-S216.

[6] IHME. Pushing the Pace: Progress and Challenges in Fighting Childhood Pneumonia. Seattle - Google Search [Internet]. 2014 [cited 2016 Aug 16]. Available from: https://www.google.com/search?

[7] GAPPD. Global Action Plan for Prevention and Control of Pneumonia and Diarrhea - Google Search [Internet]. 2014 [cited 2016 Aug 17]. Available from: https://www.google.com/search?

[8] Young M, Wolfheim C, Marsh DR, Hammamy D. World Health Organization/United Nations Children's Fund joint statement on integrated community case management: an equity-focused strategy to improve access to essential treatment services for children. Am J Trop Med Hyg. 2012; 87(5 Suppl):6-10.

[9] GHO. Care seeking for pneumonia global health observatory Google Search [Internet]. 2015 [cited 2016 Aug 16]. Available from: https://www.google.com/search?

[10] Githunguri Sub - County Health Records. Githunguri Sub - County Health Records. 2015. Anecdotal reports compiled from health facilities in Githunguri Sub - County. Kiambu, Kenya; 2015.

[11] Bbaale E. Determinants of diarrhoea and acute respiratory infection among under-fives in Uganda. Australas Med J. 2011;4(7):400-409.

[12] Astale T, Chenault M. Help-Seeking Behavior for Children with Acute Respiratory Infection in Ethiopia: Results from 2011 Ethiopia Demographic and Health Survey. PloS One. 2015;10(11):e0142553.

[13] Kumar SG, Majumdar A, Kumar V, Naik BN, Selvaraj K, Balajee K, et al. Prevalence of acute respiratory infection among under-five children in urban and rural areas of puducherry, India. J Nat Sci Biol Med. 2015;6(1):3.

[14] Källander K, Hildenwall H, Waiswa P, Galiwango E, Peterson S, Pariyo G. Delayed care seeking for fatal pneumonia in children aged under five years in Uganda: a case-series study. Bull World Health Organ. 2008;86(5):332-338.

[15] Demissie B, Zerihun BEH, Tafese Z, Gamo G, Tafese T, Kumie A, et al. Assessment of health care seeking behavior of caregivers for common childhood illnesses in Shashogo Woreda, Southern Ethiopia. Ethiop J Health Dev. 2014; 28 (Special Issue):36-43.

[16] Memon KN, Shaikh K, Pandhiani BS, Usman G. How do Mothers Recognize \& Treat Pneumonia in their Children at Home? A study in Union Council Jhudo, District Mirpurkhas. JLUMHS. 2013;12(03):208. 
[17] Doracaj D, Grabocka E, Hallkaj E, Vyshka G. Healthcareseeking Practices for Common Childhood Illnesses in Northeastern Albania: A Community-based Household Survey. J Adv Med Pharm Sci [Internet]. 2015 [cited 2016 Aug 16]; Available from: http://www.academia.edu/

[18] Malhotra N, Upadhyay RP. Why are there delays in seeking treatment for childhood diarrhoea in India? Acta Paediatr. 2013;102(9):e413-e418.

[19] Noordam AC, Carvajal-Velez L, Sharkey AB, Young M, Cals JW. Care seeking behaviour for children with suspected pneumonia in countries in Sub-Saharan Africa with high pneumonia mortality. PloS One. 2015;10(2):e0117919.

[20] Kresno S, Harrison GC, Sutrisna B, Reingold A. Acute respiratory illnesses in children under five years in Indramayu, west Java, Indonesia: a rapid ethnographic assessment. Med Anthropol. 2010;15(4):425-434.

[21] Keter P, Mbakaya C, Gikunju J, Mutai J. Knowledge, Perceptions and Practices of Mothers in Relation to Childhood Pneumonia at Kapsabet District Hospital in Nandi County, Kenya. - Google Search [Internet]. 2015 [cited 2016 Aug 16]. Available from: https://www.google.com/search?

[22] Rehman A, Shaikh BT, Ronis KA. Health care seeking patterns and out of pocket payments for children under five years of age living in Katchi Abadis (slums), in Islamabad, Pakistan. Int J Equity Health. 2014;13(1):1.

[23] Webair HH, Bin-Gouth AS. Factors affecting health seeking behavior for common childhood illnesses in Yemen. Patient Prefer Adherence [Internet]. 2013 [cited 2016 Aug 16];7. Available from: http://search.ebscohost

[24] Mebratie AD, Van de Poel E, Yilma Z, Abebaw D, Alemu G, Bedi AS. Healthcare-seeking behaviour in rural Ethiopia: evidence from clinical vignettes. BMJ Open. 2014; 4 (2): e004020.

[25] Bedford J. Qualitative study to identify solutions to local barriers to care-seeking and treatment for diarrhoea malaria and pneumonia in select high burden countries. Report on findings from Nigeria. 2012 [cited 2016 Aug 16]; Available from: http://www.popline.org/node/574688

[26] Simiyu DE, Wafula EM, Nduati RW. Mothers' knowledge, attitudes and practices regarding acute respiratory infections in children in Baringo District, Kenya. East Afr Med J. 2003;80(6):303-307.

[27] Ekure EN, Esezobor CI, Balogun MR, Mukhtar-Yola M, Ojo
OO, Emodi IJ, et al. Mothers and childhood pneumonia: what should the focus of public campaigns be? Niger J Paediatr. 2013;40(1):24-29.

[28] Bedford, Sharkey AB. Local barriers and solutions to improve care-seeking for childhood pneumonia, diarrhoea and malaria in Kenya, Nigeria and Niger: a qualitative study. PloS One. 2014;9(6):e100038.

[29] Sharkey A, Chopra M, Jackson D, Winch PJ, Minkovitz CS. Influences on healthcare-seeking during final illnesses of infants in under-resourced South African settings. J Health Popul Nutr. 2011;379-387.

[30] Van der Hoeven M, Kruger A, Greeff M. Differences in health care seeking behaviour between rural and urban communities in South Africa. Int J Equity Health. 2012;11(1):1.

[31] Najnin N, Bennett CM, Luby SP. Inequalities in Care-seeking for Febrile Illness of Under-five Children in Urban Dhaka, Bangladesh. J Health Popul Nutr [Internet]. 2011 Nov 13 [cited 2016 Aug 16];29(5). Available from: http://www.banglajol.info/index.php/JHPN/article/view/8907.

[32] Sakisaka K, Jimba M, Hanada K. Changing poor mothers' care-seeking behaviors in response to childhood illness: findings from a cross-sectional study in Granada, Nicaragua. BMC Int Health Hum Rights. 2010;10(1):1.

[33] Taffa N, Chepngeno G. Determinants of health care seeking for childhood illnesses in Nairobi slums. Trop Med Int Health. 2005;10(3):240-245.

[34] Irimu G, Nduati RW, Wafula E, Lenja J. Community understanding of pneumonia in Kenya. Afr Health Sci [Internet]. 2008 [cited 2016 Aug 16];8(2). Available from: http://www.ajol.info/index.php/ahs/article/view/7058.

[35] Alvesson HM, Lindelow M, Khanthaphat B, Laflamme L. Shaping healthcare-seeking processes during fatal illness in resource-poor settings. A study in Lao PDR. BMC Health Serv Res. 2012;12(1):1.

[36] Kim SA, Capeding MRZ, Kilgore PE. Factors influencing healthcare utilization among children with pneumonia in Muntinlupa City, Philippines. Southeast Asian J Trop Med Public Health. 2014;151:919.

[37] Kosai H, Tamaki R, Saito M, Tohma K, Alday PP, Tan AG, et al. Incidence and Risk Factors of Childhood Pneumonia-Like Episodes in Biliran Island, Philippines-A Community-Based Study. PloS One. 2015;10(5):e0125009. 